\title{
CORROSION RESISTANT TWO-LAYER GLASS-CERAMIC COATING
}

\author{
Marta Kuznetsova $^{1}$, Iryna Lutsyuk ${ }^{2}$
}
1. Department of Heat Engineering and Thermal and Nuclear Power Plants, Lviv Polytechnic National University, UKRAINE, Lviv, 12 Bandera str., E-mail: kuznetsovam83@gmail.com
2. Department of Chemical Technology of Silicate Material, Lviv Polytechnic National University, UKRAINE, Lviv, 12 Bandera str., E-mail: ira_lutsuk@ukr.net

\begin{abstract}
Na}_{2} \mathrm{O}-\mathrm{SiO}_{2}-\mathrm{P}_{2} \mathrm{O}_{5}-\mathrm{MoO}_{3}$ system has been developed. The minimum glass-forming temperature for the protective coating layer is determined. It has been established that the soil layer increases the adhesion of the coating to the metal substrate.
\end{abstract}

Keywords - solution technology, glass-ceramic coating, soil coating, glass-making solutions, adhesion.

The using of inorganic coatings is effective for protecting metal parts and equipment from the effects of aggressive action of gases, solutions, melt and solids and also it increased their useful life. The glass-enamel coatings are particular importance and spread due to the unique combination of their mechanical strength, thermal and chemical resistance, lack of aging, surface smoothness and hygienic properties. In this regard, the development of warehouses of glass coatings for the protection of metal equipment from corrosion is a topical task today.

The purpose of the work was developed a composition of corrosion-proof double-layer glass-ceramic coating with high adhesion to a metal substrate with using soluble technology.

The multicomponent silicate glass system of $\mathrm{Na}_{2} \mathrm{O}-\mathrm{B}_{2} \mathrm{O}_{3}-\mathrm{TiO}_{2}-\mathrm{SiO}_{2}$ with a refractory filler $\mathrm{ZrO}_{2}$ was chosed to achieved the intended purpose as a corrosion-resistant layer. The temperature formation of a defect-free ceramic coating is $760{ }^{\circ} \mathrm{C}$. However, the results of studies had showed that the resulting coating was characterized by low values of adhesion to the metal substrate (0.4 MPa).

In order to increase the adhesion of the glass-ceramic coating for the steel substrate were used a layer of soil, for receiving which, had selected a system based on phosphate glass. A characteristic feature of this system are elevated value of the temperature coefficient of linear expansion, high adhesion to the metal and low temperature of formation. The research has been established that these requirements correspond to the soil composition of the composition (\% by weight): $\mathrm{Na}_{2} \mathrm{O}-36, \mathrm{SiO}_{2}-45, \mathrm{P}_{2} \mathrm{O}_{5}-9, \mathrm{MoO}_{3}-10$. As the starting reactants have been used $\mathrm{Na}_{2} \mathrm{MoO}_{4} \cdot 2 \mathrm{H}_{2} \mathrm{O}, \mathrm{Na}_{2} \mathrm{HPO}_{4} \cdot 12 \mathrm{H}_{2} \mathrm{O}, \mathrm{NaOH}, \mathrm{H}_{3} \mathrm{PO}_{4}$ and sodium fluoride with module 2 . The above reagents were dissolved in water, based on their solubility and mixed in a certain stoichiometric relationship with the liquid glass. The obtained glass-making solution was applied to a heated metal substrate to $300{ }^{\circ} \mathrm{C}$ with subsequent melting in a gradient furnace at temperatures about 300 $800{ }^{\circ} \mathrm{C}$. As a result of heat treatment at $780{ }^{\circ} \mathrm{C}$, the layer of soil firmly fixed on the surface of the metal was obtained. Adhesion of the soil layer to the metal surface is $3.4 \mathrm{MPa}$.

Thus, the two-layer corrosion-resistant glass-ceramic coating with high performance characteristics had obtained with using a solution technology at low energy and material costs during formation due to the consistent application of soil and protective layer. 